\title{
Leadership and co-operation in orchestras
}

\author{
Sabine Boerner \\ University of Konstanz
}

Diana E. Krause

Berlin Technical University

Diether Gebert

Berlin Technical University

\begin{abstract}
The leadership of musicians by the conductor of an orchestra is a combination of authority and charisma. It is a special case of directive-charismatic leadership that needs to be explained because it involves substantive restriction of freedom for the led, whereas in other creative fields (e.g. research and development) a non-directive style of leadership is considered functional to success. Current theory on leadership (e.g. contingency theory) is not able to explain this phenomenon. We develop a model of leadership in the orchestra, from which a specific (directive-charismatic) leader behavior is to be derived from the singularities of this leadership goal and the behavior required of followers. On the basis of a sample of $n=334$ musicians from thirty German orchestras, we show empirically that directive-charismatic leadership in the orchestra has a positive impact on the quality of ensemble playing, thus promoting artistic quality as leadership success. Conclusions are drawn both for leadership theory and for the selection and training of orchestral musicians and conductors.
\end{abstract}

Keywords: directive-charismatic leadership, artistic quality, co-ordination, cooperation, orchestra

A conductor's leadership style with orchestra musicians is largely directive (Boerner and Krause 2002). Generally, musicians do not participate in developing a conception for the interpretation and they do not have much freedom in realizing the conception. Instead, they have to realize the conductor's ideas for interpretation and they are immediately controlled and criticized by the conductor (Boerner and Krause 2001; Couch 1983: 10).

Compared to other organizational fields, this directive-charismatic leadership style of an orchestral conductor is unusual and needs to be explained: where creativity is crucial in organizations (e.g. in research and development), generally a non-directive style of leadership is considered functional for success (Amabile and Gryskiewicz 1989). A non-directive leadership style tends to be functional because the employees in creative fields are highly qualified and intrinsically motivated (Amabile 1994). Thus, to make best use of their skills, and to maintain and enhance their motivation, it seems adequate to leave the led as much freedom as possible (Krause 2004). In the orchestra, as in other creative fields, the musicians are well-trained professionals with 
a high degree of intrinsic motivation (Allmendinger et al. 1996). This raises the question of why the conductor's leadership style is not participative or delegative, but directive.

This question is particularly interesting in the tradition of the contingency theories of leadership (see Yukl 2002). The main idea of the contingency theories of leadership (e.g. Fiedler 1967) is that there is not 'one best leadership style' which is functional in every context. Instead, they assume that the relation between leadership style and leadership success varies from one context to the other. Different approaches of the contingency leadership theories have integrated various context variables (see Yukl 2002): characteristics of the task (e.g. complexity, structure, technology), characteristics of the followers (e.g. motivation, skills, knowledge, experiences, self-esteem), characteristics of the group (e.g. group size, composition of the group, level of trust) and characteristics of the organization (e.g. organizational structure and organizational culture). In the present study, characteristics of the followers are analyzed to explain the relationship between leadership behavior and leadership success in orchestras.

Directive leader behavior in the orchestra can be explained in terms of the leadership goal - artistic quality - that is pursued. With reference to the model of goal-directed leadership (Gebert and Ulrich 1991) we assume that the specific nature of leadership success in the orchestra requires precise ensemble playing by the musicians. This follower behavior needed to achieve success is also examined with regard to its professional and motivational prerequisites: skill and motivation. Against this background it can be demonstrated that a leadership style that is directive and - at the same time - charismatic is functional to success in the orchestra because it promotes the professional and motivational prerequisites for precise co-operation among the members of the orchestra (Boerner and v. Streit, 2004). Our hypotheses first look at co-operation as a precondition for artistic quality in the orchestra, then explain the role of the musicians' skill and motivation for the co-operation. Finally, the effectiveness of directive-charismatic leadership in the orchestra is developed. Our hypotheses are tested on the basis of a sample of $n=334$ musicians from thirty German orchestras.

On the one hand, consequences for leadership theory can be drawn from the findings. On the other hand, practical implications for the selection and the training of orchestra musicians as well as for their conductors become obvious. They suggest the inclusion not only of professional competencies, but also of 'soft' factors such as charismatic leadership and the ability to work in a team.

\section{Co-operation as a precondition for artistic quality}

The focus of the artistic endeavor is the success of an orchestra. The artistic quality of performance by an orchestra can be described in terms of specific musical criteria such as sound, tempo or rhythm (Boerner 2002). But the decisive factor in the artistic quality of performance is arguably the congruity or fit of interpretation (Adorno 1968). In other words, we suggest that individual quality criteria such as 
sound and tempo are not isolated phenomena but must be so co-ordinated through synchronized playing that the guiding conception of an interpretation is perceptible.

An essential characteristic of the performance of orchestral music is that a joint interpretation is produced by a multiplicity of musicians. Depending on the work, an average of seventy players participate in a performance. The success criterion of fit between all participating in the artistic production process (see above) implies strong interdependence between tasks in the orchestra. In the interest of congruity a balance has to be maintained throughout a performance among all the members of the orchestra in sound and rhythm (Boerner and Krause 2002). A specific tonal quality, for example, can be achieved only if all the musicians involved synchronize intonation, articulation and dynamics.

This applies within sections (e.g. fit between first and second violins), between sections (fit between strings, wind instruments and percussion) and in relation to any other performers involved (soloists, choir) (Boerner in press). It is particularly difficult to achieve tonal and rhythmic balance during shifts in volume (e.g. crescendo) or tempo (e.g. accelerando), which have the desired effect only if all performers execute them with the same precision.

The degree of synchronization between all musicians is thus an essential quality in orchestral performance. The precision of ensemble playing is thus the decisive aspect of follower behavior (Figure 1). However, co-ordination in the orchestra makes special demands: since individual musicians have to execute their tasks at the same time, there is simultaneous interdependence (Saavedra et al. 1993) among performers. For this reason it is not enough to co-ordinate partial results of individual participants; it is the process of producing these results itself that has to be co-ordinated. This argumentation introduces our first hypothesis:

Hypothesis 1: Co-ordination among the orchestral musicians will be positively related to the artistic quality of the orchestra.

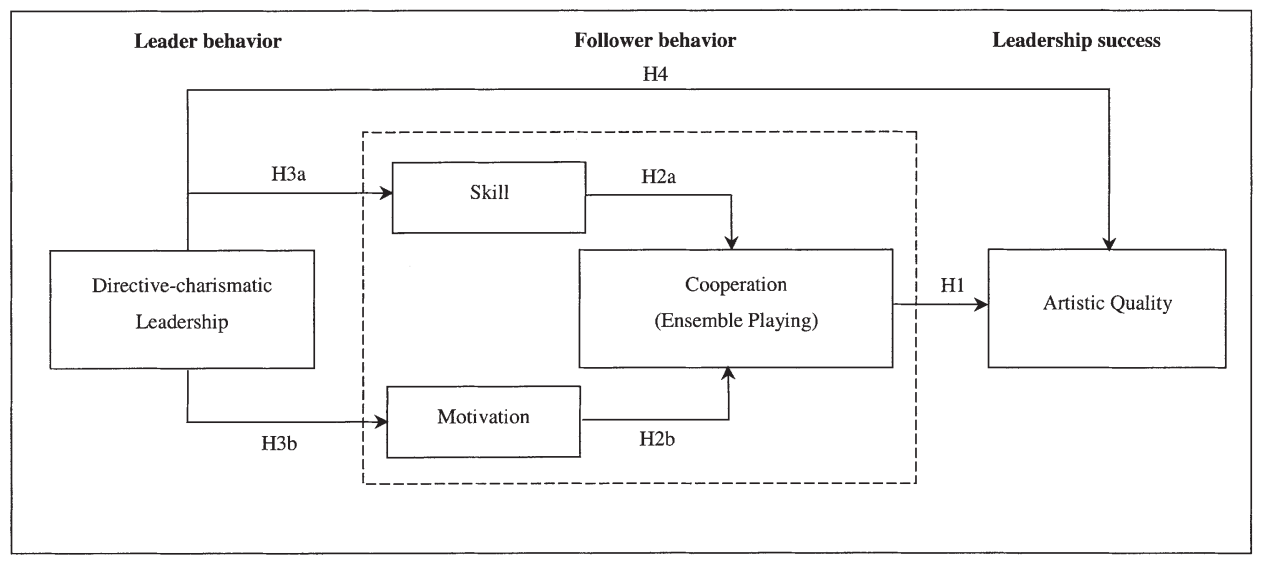

Figure 1 Leader behavior, follower behavior and leadership success in the orchestra model and hypotheses 


\section{Skill and motivation as conditions for co-operation in the orchestra}

Precise ensemble playing by musicians requires not only individual mastery of the given instrument but also the ability to co-operate. Musicians must co-ordinate their movements (e.g. bowing), their breathing and the intensity of playing. To do so, they need to know the target value of the interpretation, and in implementing this target value they must not only listen carefully to the other instruments but also react directly to each others' playing (Boerner 2002).

In addition to skill, motivation is a decisive prerequisite for co-ordination among musicians, and thus for artistic quality (Boerner 2002). Players do not only need to know the desired interpretation but also must be willing to realize it. As in other artistic professions, musicians can be expected to have a high level of intrinsic motivation in principle (Boerner 2000; Allmendinger et al. 1996). The experience of 'flow' especially - total absorption in the task (Csikszentmihalyi 1997) - appears to be typical of musicians. Flow arises when musicians can fully unfold their skills in their activity, i.e. when neither too much nor too little is demanded of them. In an orchestra, a directive leadership style is necessary for co-ordination but is likely to entail negative secondary motivational effects among the players. If the conductor is accepted as an uncontested authority in his métier by the musicians, he might be able to compensate for such negative effects. To this extent the skill and motivation of musicians (Figure 1) are interdependent.

Hypothesis 2: The musicians' skill (2a) and the musicians' motivation (2b) will enhance the co-operation within the orchestra.

\section{Directive-charismatic leadership of the conductor}

A leadership style that combines directiveness and charisma fosters both ensemble-playing skill and motivation among musicians. This leadership style will be called 'directive-charismatic leadership' in the remainder of this paper. Notions about the 'correct' interpretation of a work and about the quality achieved in a performance may differ from person to person. Therefore, the evaluation of artistic quality depends on personal characteristics of the performers, such as education, previous experience, prior information, and on personal states of mind and taste (Lesle 1984). Any decentralized agreement between musicians on interpretation would thus at the very least be highly timeconsuming if not completely impossible. Moreover, the technical conditions in an orchestra generally run counter to decentralized self-coordination. Because of how they are seated, individual musicians cannot clearly see and hear one another, which, in the case of decentralized self-coordination, would jeopardize the precision of synchronization.

As a result, a decentralized self-coordination would not suffice, however skilled the musicians might be. Instead of decentralized self-coordination, a centralized coordination by a person external to the orchestra seems to be needed. Thus, the decisive task of the conductor is the centralized co-ordination of orchestral playing. The conductor determines the artistic conception of the particular interpretation and 
thus sets the target; he detects deviations from this target and corrects them directly. The target thus becomes apparent to all musicians.

Leader behavior that enhances ensemble-playing skills is nevertheless highly directive (Boerner 2000), because the musicians are externally controlled. This can have a negative impact on their motivation. If the conductor determines both the goal and how to reach it, the freedom of orchestral musicians is restricted. Thus, orchestral musicians have hardly any opportunity to implement their own interpretation, i.e. themselves to set and realize the target. This is particularly problematic because musicians tend to be trained for solo performance (Stepanauskas 2001).

With this in mind it becomes clear why directive and charismatic leadership by the conductor is needed. Although the conductor leads directively, his authority is not arbitrary (Weber 1989) nor is it based on his formal position of leadership (Krause and Boerner 2001), but on the qualities the musicians ascribe to him (Bass and Avolio 1993; House et al. 1991; Krause and Boerner 2001). We assume that, if a conductor radiates confidence, superiority, power, reliability and charisma, musicians expect that the result, i.e. the artistic quality of the interpretation, will convince them. In the sense of a self-fulfilling prophecy (Merton 1957), they are accordingly motivated and feel challenged to perform well. Under these conditions they align their playing with the target set and with the performance of their fellow musicians, and thus achieve the expected result. In this paper, we refer to a leader who is ascribed the above-mentioned qualities as a directive-charismatic leader. Our assumption is that the charismatic nature of the conductor's directive leadership induces musicians to accept restrictions on their individual freedom in the process of artistic production in the interest of a high artistic result, so they accept the target set by the conductor.

Hypothesis 3: Directive-charismatic leadership enhances both the musicians' skill (3a) and their motivation $(3 \mathrm{~b})$.

Hypothesis 4: A directive-charismatic leadership style enhances the artistic quality of an orchestra.

If, however, the musicians see the conductor merely as, say, sympathetic, they would not expect a high artistic result and would therefore not accept any restriction on their freedom. It is the charismatic legitimation of directive leadership that reduces the negative secondary motivational effects. The more charismatic the conductor's leadership style is, the more the musicians will identify with him. Empirical investigations reveal that a high level of identification by employees with their leader enhances leadership success (Krause 2003). We therefore assume that a directive-charismatic leadership style enhances the artistic quality of an orchestra more than a sympathetic leadership style does.

\section{Method}

To test the above hypotheses, a nationwide survey in 2000 and 2001 questioned 334 orchestral musicians from thirty German orchestras in writing (return rate about 30 
per cent). The questionnaire included twenty-three items. Since a particular instrument to investigate leadership behavior, employees' behavior and leadership success in the orchestra was not available, we self-designed it for the given context and used it for the first time. In principle, we could have applied established instruments to measure leadership behavior; using the self-designed orchestraspecific instrument, however, allows for a higher construct validity and thus for a higher degree of explained variance.

Surveys were distributed to each orchestra manager asking for participation and promising confidentiality. In order to guarantee confidentiality, the orchestra managers sent the surveys directly to our institute.

A maximum of twenty musicians per orchestra responded. About two-thirds (65 per cent) of the orchestras were attached to a theatre, while one third ( 35 per cent) were exclusively symphony orchestras. Respondents were on average 40 years old and had seventeen years of professional experience. Sixty-nine per cent of the musicians were male, 31 per cent female. The sample corresponds largely to the actual composition of an orchestra in terms of the section of the musicians (58 per cent strings, 26 per cent woodwind, 12 per cent brass, 4 per cent percussion) and in terms of the position in the orchestra: more than half of the musicians ( 55 per cent) were tutti players, who perform only the 'tutti parts' of the score, when the whole orchestra performs, but never perform as soloists; 23 per cent were soloists and 22 per cent were principals, i.e. leaders of an instrument group.

In the questionnaire, the musicians were requested to evaluate the leader behavior of a conductor of their choice, their own behavior as followers and the artistic quality of their orchestra. Since an orchestra is led by different conductors (about ten to fifteen per year), it was likely that the resulting variance in leadership behavior and artistic quality would reflect not only personal respondent variance but, essentially, varying behavior by conductors.

\section{Measurement of leadership success in the orchestra}

Artistic quality was assessed from two points of view. The musicians stated how they themselves judge the artistic quality of their orchestra (self-assessment) and how people outside the orchestra judge it (presumed external assessment) (see Table 1). The artistic quality of the orchestra was operationalized by multi-item measurement. The response format for this scale was a 7-point Likert scale ranging from 1, 'very low', to 7, 'very high'. On the basis of the good reliability of this scale (standardized Cronbach's $\alpha=.90$ ), the items were aggregated to a sum score.

As we have seen, evaluation of an orchestra's artistic quality can be problematic. The fact that artistic quality differs depending on the level of the orchestra speaks for the validity of our quality measurement. In Germany, there are four orchestral levels, from A (highest) to D (lowest). All the orchestras participating in this study were classified A/Fl, A or B. Level A/Fl (level A with 'footnote l') is above level A and implies corresponding increments in reputation and income. A one-factor variance analysis (with Scheffe's post hoc test) reveals significant quality differences in the expected direction between all three orchestral levels $(F(2,300)=22,34 ; p<.001)$. 
Table 1 Measurement of the artistic quality

\begin{tabular}{|c|c|}
\hline Construct & Items \\
\hline Leadership success: & $\begin{array}{l}\text { How do you personally judge the artistic quality of the orchestra's } \\
\text { performance? } \\
\text { Overall } \\
\text { In terms of your personal quality standards/expectations } \\
\text { In terms of your individual musical skills } \\
\text { In terms of the musical skills of the whole orchestra }\end{array}$ \\
\hline $\begin{array}{l}\text { Artistic quality } \\
\text { of the orchestra }\end{array}$ & $\begin{array}{l}\text { How is the artistic quality of the orchestra's performance judged by } \\
\text { other people (outside the orchestra)? } \\
\text { Overall } \\
\text { In terms of the reaction of other performers (e.g., soloists) } \\
\text { In terms of audience reaction } \\
\text { In terms of your conductor's reaction } \\
\text { In terms of reaction by the press (critics) }\end{array}$ \\
\hline
\end{tabular}

Note: Responses were on a seven-point scale from " $1=$ very low" to " $7=$ very high".

The artistic quality of higher-level orchestras is accordingly judged better than those of lower-level orchestras.

\section{Measurement of follower behavior}

The operationalization of follower behavior included the co-operation (ensemble playing) and its prerequisites (skills and motivation). These aspects were measured by single items:

- Co-operation 'How do you evaluate the level of collaboration/co-operation between the musicians in your orchestra?' (The response set for these items ranged from 1, 'very low', to 7, 'very high').

- Skill 'How do you judge the individual standard (ability, skill) of the musicians in your orchestra?' (1 representing 'very low' and 7 representing 'very high').

- Motivation 'To what extent do you feel that your artistic and expressive capabilities are given full rein? (with 1 representing 'too little scope' and '7 = 'excessive demand').

\section{Measurement of the conductor's leadership behavior}

The conductor's leadership behavior was measured by means of a semantic differential scale (Osgood et al. 1957). The response format was bipolar, ranging from -3 to +3 . The dimensionality of the construct leadership behavior was checked by a principal component analysis, in which the Kaiser criterion is used to extract only those factors whose eigenvalues were greater than one and lay in front of the 'elbow' in the Scree test (Cattell criterion). Oblique rotation of the factor loading matrix was used to interpret the results of the principal components analysis. It was assumed that 
the conductor's leadership behavior is two-dimensional. This assumption was unequivocally confirmed (see Table 2). The two factors can account for 70 per cent of the variance. The reliability coefficients (standardized Cronbach's $\alpha$ ) are $\alpha=.87$ for the first factor and $\alpha=.89$ for the second factor. On the basis of these reliabilities, the respective items were aggregated to the factors 'directive-charismatic' and 'sympathetic'.

\section{Results}

Our results underline the quality-enhancing impact of directive-charismatic leadership in the orchestra. The great importance of co-operation for the artistic quality of the orchestra (hypothesis 1) is reflected by the high correlation of these variables $(r=.51, p<.001, n=126)$. The more precise the musicians' ensemble playing is, the higher is the artistic quality of the orchestra.

As hypothesis 2 suggested, co-operation and/or co-ordination in the orchestra improve with increasing skill $(r=.60, p<.001, n=132$, hypothesis $2 \mathrm{a})$ and increasing motivation $(r=.36, p<.001, n=134$, hypothesis $2 \mathrm{~b})$. Table 1 shows that skill and motivation also have a direct positive connection with artistic quality. The importance of co-operation for artistic quality is, in turn, shown by the fact that this relationship declines without simultaneous, precise co-operation: if one controls for the variable 'co-operation', the link between skill and artistic quality weakens considerably $(r=.32, p<.001, n=121)$, while that between motivation and artistic quality declines much less $(r=.32, p<.001$, $n=123)$.

In accordance with hypothesis 3 , directive-charismatic leadership positively affects both the skill $(r=.36, p<.001, n=130$, hypothesis $3 \mathrm{a})$ and the motivation $(r=.33$,

Table 2 Measurement of the conductor's leadership behavior

\begin{tabular}{|c|c|c|c|}
\hline $\begin{array}{l}\text { Construct: Conductor's } \\
\text { Leadership Behavior }\end{array}$ & $\begin{array}{l}\text { Instruction/Item } \\
\text { Please assess the conductor in relation to all } \\
\text { adjective pairs: I consider the conductor to be... }\end{array}$ & Factor 1 & Factor 2 \\
\hline $\begin{array}{l}\text { Factor 1: } \\
\text { Leadership: } \\
\text { directive-charismatic }\end{array}$ & $\begin{array}{l}\text { powerful-powerless } \\
\text { superior-inferior } \\
\text { confident-insecure } \\
\text { charismatic-not charismatic } \\
\text { reliable - unreliable }\end{array}$ & $\begin{array}{l}.90 \\
.90 \\
.81 \\
.72 \\
.68\end{array}$ & $\begin{array}{r}-.28 \\
-. \\
.16 \\
.11 \\
.22\end{array}$ \\
\hline $\begin{array}{l}\text { Factor 2: } \\
\text { Leadership: } \\
\text { sympathetic }\end{array}$ & $\begin{array}{l}\text { considerate-inconsiderate } \\
\text { tolerant-intolerant } \\
\text { fair-unfair } \\
\text { pleasant-unpleasant } \\
\text { sympathetic-unsympathetic }\end{array}$ & $\begin{array}{r}-.15 \\
-.16 \\
.16 \\
.21 \\
.23\end{array}$ & $\begin{array}{l}.91 \\
.82 \\
.79 \\
.78 \\
.75\end{array}$ \\
\hline
\end{tabular}

Note: Principal component analysis and oblique rotation were performed in the factor analysis. 
$p<.001, n=326$, hypothesis $3 \mathrm{~b}$ ) of orchestral musicians. The followers know the interpretation target of the conductor and want to attain it, thus feeling that their best is demanded of them. Both conditions are important for co-operation, i.e. motivation cannot substitute for skill and vice versa. If one controls for the effect of the variable 'motivation', the connection between skill and artistic quality declines $(r=.42, p<.001, n=121)$; if one controls for the effect of 'skills', the connection between motivation and artistic quality also declines $(r=.29, p<.001, n=121)$. Leader behavior affects the two preconditions for follower behavior about equally, because about 10 per cent of both follower skill and motivation variance are explained.

As was stated in hypothesis 4 , the more strongly the conductor leads in a directive-charismatic manner, the higher is the artistic quality of the orchestra $(r=.64, p<.001, n=306$; see Table 3$)$. In addition, the results show that 'sympathetic' leadership, too, promotes artistic quality in the orchestra $(r=.31$, $p<.001, n=308)$. But, while this type of leadership explains only 9 per cent of quality variance, no less than 40 per cent is explained by directive-charismatic leadership. To further analyze the relative effects of directive-charismatic leadership and sympathetic leadership on the artistic quality, a multiple regression analysis was calculated. The artistic quality of the orchestra was regressed on directivecharismatic leadership and sympathetic leadership. The significant regression model (see Table 4) shows a strong and significant coefficient for directive-charismatic leadership, whereas the coefficient for sympathetic leadership is not significant. This result can be interpreted as a confirmation of our assumption that a directivecharismatic leadership style increases the artistic quality of an orchestra more than a sympathetic leadership style does.

\section{Conclusions}

To begin with, a number of relativizing remarks on method are called for. Because all the information (the judgements of both the independent and dependent variables) was collected from the same respondents, the level of the ascertained connections could in principle also be due to an overestimation of

Table 3 Intercorrelations of the variables

\begin{tabular}{lrrrrrrrr}
\hline & $N$ & $M$ & $S D$ & 1 & 2 & 3 & 4 & 5 \\
\hline 1 Leadership: directive-charismatic & 327 & .61 & 1.32 & - & & & \\
2 Leadership: sympathetic & 324 & .52 & 1.37 & $.40^{* * *}$ & & & & \\
3 Skill & 132 & 4.81 & 1.34 & $.36^{* * *}$ & -.01 & & & \\
4 Motivation & 132 & 3.39 & 2.02 & $.33^{* * *}$ & $.12^{*}$ & $.37^{* * *}$ & & \\
5 Cooperation (ensemble playing) & 134 & 4.31 & 1.58 & $.38^{* * *}$ & -.06 & $.60^{* * *}$ & $.36^{* * *}$ & \\
6 Artistic quality of the orchestra & 334 & 4.66 & 1.11 & $.64^{* * *}$ & $.31^{* * *}$ & $.52^{* * *}$ & $.42^{* * *}$ & $.51^{* * *}$
\end{tabular}

Notes: Pearson correlations. Two-tailed significance. Fluctuations in sample size $(\mathrm{N}=130$ versus $\mathrm{N}=326)$ result from the variablesSkill, motivation, and cooperation being investigated only in a sub-sample of $\mathrm{N}=134$ orchestral musicians.

${ }^{*} \mathrm{p}<.05,{ }^{* * *} p<.001$. 
Table 4 Results of the multiple regression analysis: directive-charismatic leadership behavior and sympathetic leadership behavior as predictors of artistic quality

\begin{tabular}{|c|c|}
\hline & Criteria \\
\hline & Artistic Quality \\
\hline Predictors & $\beta$ \\
\hline $\begin{array}{l}\text { Leadership: directive-charismatic } \\
\text { Leadership: sympathetic }\end{array}$ & $\begin{array}{l}.60^{* * *} \\
.06\end{array}$ \\
\hline \multicolumn{2}{|l|}{ Values of the model } \\
\hline $\begin{array}{l}R \\
R^{2}\left(R^{2} \text { adj }\right) \\
F \\
d f 1, d f 2 \\
N\end{array}$ & $\begin{array}{c}.63 \\
.39(.38) \\
128.57^{* * *} \\
2,331 \\
334\end{array}$ \\
\hline
\end{tabular}

Notes: $\beta=$ standardized regression coefficient. $R=$ multiple correlation coefficient. $R^{2}=$ part of explained variance.

$R^{2}$ adj $=$ adjusted $R^{2}$.

$* * * p<.001$.

the connections between predictor and criterion (because of common-method variance). This problem has been discussed as common-method bias or single subject response consistency bias (McDonald 1999). For this reason, a factor analysis across all items of the study was calculated. A general factor ( $G$ factor) in this factor analysis would indicate the common method bias. However, no trace of a $\mathrm{G}$ factor was extracted. Although no $\mathrm{G}$ factor existed, future studies would have to collect the data on leadership style, skill and motivation and coordination and that on artistic quality from independent sources like different groups of people (e.g. orchestra musicians, the conductor, the press, the audience).

A second limitation of our study is the use of single-item measures; future research should develop multi-item measurements for follower behavior. Third, our operationalization of leadership behavior focuses more on the conductor's characteristics than on his leadership behavior. Further research should thus concentrate on measures which are more behavior related. However, research on transformational leadership shows that behavior-related measures, like the Multifactor Leadership Questionnaire, have inherent problems (Bass and Avolio 1990).

Fourth, as in many empirical investigations, independent and dependent variables are measured at the same time. Instead, follow-up studies should collect data on the artistic quality of the orchestra later than the data on leadership behavior and follower behavior, using a longitudinal design. Despite these problems, the results of the present investigation have theoretical and practical implications for the co-operation and leadership in the orchestra.

Fifth, it must be said that our sample of German orchestras does not stem from random selection. This raises the question as to what extent the results 
found for German musicians are representative for musicians from other countries. We cannot, however, answer this question preliminarily, since no scientifically founded results exist so far. It would be interesting for further studies to test if the relationships that were found between leadership behavior, musicians' behavior and artistic quality of the orchestra are valid for orchestras in other countries as well, or if the results represent only specific German characteristics. To receive hints on this question, however, crosscultural comparative studies in the field of orchestras would have to be conducted.

\section{Theoretical implications}

An orchestra can be considered as an example of an organization that needs lifelong learning in order to reach a good performance. The success of an orchestra requires new interpretations of existing works, interpretation of new compositions and collaboration with different leaders. The paper shows that lifelong learning in the orchestra requires special forms of both horizontal and vertical interaction.

Horizontal interaction, for example, co-operation, in the orchestra is not limited to some form of team work. Since in the orchestra an average of seventy musicians have to be co-ordinated, an orchestra is an example of inter-team co-operation in an organization. The present study reveals how individual motivation and skills contribute to successful inter-team co-operation.

The particular form of horizontal interaction calls for a special form of vertical interaction in the orchestra, e.g. a directive-charismatic leadership style. Leadership theory predicts a non-directive leadership style to be functional if the led are highly qualified and highly (intrinsically) motivated (e.g. Hersey and Blanchard 1977; Vroom and Yetton 1978). Against the background of contingency theory, the question is whether other contingency variables can be discovered to explain the phenomenon. This is where our research can make a contribution to leadership theory. First, in addition to the characteristics of the employees, the particularity of co-ordination between their tasks has to be taken into account. Whereas the characteristics of the individual tasks (like complexity or structure) are often considered in contingency approaches of leadership theory, the co-ordination between tasks is overlooked.

Second, our investigation reveals that the quality of leadership itself has to be analyzed more precisely. For example, the 'traditional' classifications of 'directive' versus 'participative' leadership style (Tannenbaum and Schmidt 1958) or 'consideration' and 'initiating structure' (Fleishman 1973) do not appear sufficient in the field of orchestral leadership. Instead, it seems crucial to specify leadership behavior for the relevant context (Gebert 2002), because different contexts call for different criteria for leadership success (Yukl 2002).

Third, our study shows that there are constellations where a directive-charismatic leadership is functional, despite the problematic aspects of this leadership style. For instance, the danger of 'losing the led' by a strong directive-charismatic leadership (de Vries et al. 1999) becomes less relevant given the particular characteristics of the situation in an orchestra. 


\section{Practical implications}

For the practice of co-operation and leadership in the orchestra, the following consequences are relevant. The more artistic quality actually needs improving, the more important our findings are for the practice of leadership in the orchestra. Respondents took a largely positive view on the artistic quality of their orchestras - based on presumed external assessment (for example, by the public or through the press). The orchestral musicians estimated that more than two-thirds (81 per cent) of people external to the orchestra judged its artistic quality as a whole to be high (presumed external assessment). Measured against their personal demands and abilities (self-assessment), however, musicians are more critical about the artistic quality of their orchestras. Only about half of the artists ( 52 per cent) assess the artistic quality of the orchestra as 'good'. Almost half, in contrast, consider it to need improvement. Therefore, respondents self-rated their orchestras lower than they thought the public would.

According to these considerations, the starting point for increasing artistic quality is the promotion of follower behavior pertinent to success and its prerequisites (cf. Figure 1): the cooperation, skill and motivation of the musicians in the orchestra.

Whereas skill was assessed as good by the majority of musicians, over half ( 52 per cent) of the musicians judged cooperation within the orchestra to be bad and almost half of the respondents regarded improvement of motivation as needful. Forty-nine per cent felt that not enough was demanded of them in the orchestra. Apparently the skills were available, but could not be fully exercised because the musicians did not fully accept the right of their conductors to restrict them in artistic terms.

These results suggest that there might be a potential for high artistic quality in the orchestras we studied, which, however, is not exploited at an optimum. The utilization of the synergy potential, which is given through the musicians' skills, needs mobilization on the one hand and a bundling of individual resources on the other hand. As a consequence for the training and the selection of orchestra musicians, it means that, in addition to individual training on the instrument, the orchestral playing must be given much more consideration than has hitherto been the case (Stepanauskas 2001). Further training measures in the sense of systematic employee development do usually not take place in orchestras. Since orchestral musicians train themselves particularly through the requirements of the repertoire and the conductor, personnel development remains mainly a matter of leadership.

Second, the results of our study call for leadership training for conductors. In many organizational fields, special training is developed to improve leadership competence. In the field of orchestral leadership, however, this is not common at all. Conductor training is limited mainly to the artistic or musical aspect of leading an orchestra. According to a former empirical investigation (Krause et al. 2002), the conductor's directive-charismatic leadership should be based not only on expert knowledge, but on the musicians' identification with the conductor at the same time. A consequence of our investigation could thus be to require special training 
for conductors in order to improve co-operation and motivation among the musicians.

Not only could development measures for conductors be designed and implemented, but the selection of conductors might also be something to think about. Looking at our results, it is essential for the artistic quality of an orchestra that the musicians perceive the conductor as charismatic, and can identify themselves with him. It is not just the conductor's professional competence that determines success, but also his or her charisma. Therefore, it could also be helpful - as is usual for other occupational groups - to implement an appropriate employee selection process, and to map the person-related core competencies in job specifications. For that purpose, it is advisable to avoid standard competencies such as communication abilities, and identify instead constructs relevant for success, such as charisma, intrinsic motivation, self-efficacy and internal locus of control. If a conductor with such abilities was deliberately selected, and if these abilities were enhanced in subsequent training, the result could be a contribution that is critical to successfully increasing leadership competence within the orchestra.

\section{Addresses for correspondence}

Sabine Boerner, Chair of Management, Strategy, and Leadership, Faculty of Politics and Management

University of Konstanz Universitätsstraße

1078457

Konstanz Germany

Diana E. Krause and Diether Gebert

Faculty of Economics and Management

Department of Human Resource Management and Organizational Behavior

Wilmersdorfer Str. 148

Berlin Technical University

10585

Berlin Germany

\section{References}

Adorno, T. W. (1968) 'Reflexionen über Musikkritik', in H. Kaufmann (ed.) Symposion für Musikkritik, Graz: Institut für Wertungsforschung, pp. 7-21.

Allmendinger, J., Hackman, R. J. and Lehman, E. V. (1996) 'Life and work in symphony orchestras', The Musical Quarterly 80: 194-219.

Amabile, T. M. (1994) "The "atmosphere of pure work": creativity in research and development', in W. S. Shadish and S. Fuller (eds) The Social Psychology of Science, New York and London: Guilford Press, pp. 316-28.

Amabile, T. M. and Gryskiewicz, S. S. (1989) 'The creative environment scales: work environment inventory', Creativity Research Journal 2: $231-53$. 
Bass, B. M. and Avolio, B. J. (1990) Transformational Leadership Development: Manual for the Multifactor Leadership Questionnaire, Palo Alto, CA: Psychologists Press.

Bass, B. M. and Avolio, B. J. (1993) Transformational Leadership: A Response to Critiques, New York: Free Press.

Boerner, S. (2000) 'Führung und künstlerische Qualität im Musiktheater - eine Analyse am Beispiel des Opernorchesters', Zeitschrift für öffentliche und gemeinwirtschaftliche Unternehmung 23: 68-78.

Boerner, S. (2002) Führungsverhalten und Führungserfolg - Beitrag zu einer Theorie der Fübrung am Beispiel des Musiktheaters, Wiesbaden: Gabler.

Boerner, S. (in press) 'Artistic quality in an opera company - towards the development of a concept', Nonprofit Management and Leadership 4(4).

Boerner, S. and Krause, D. E. (2001) 'Musik als Berufung - zur Motivation im Orchester. Eine empirische Studie', Das Orchester 49(11): 8-11.

Boerner, S. and Krause, D. E. (2002) 'Führung im Orchester: Kunst ohne künstlerische Freiheit?', Zeitschrift für Personalforschung 16(1): 90-106.

Boerner, S. and v. Streit, C. (2004) 'Transformational leadership and group emotion as prerequisites for success in the symphony orchestra', paper presented at the 8th International Conference on Music Perception and Cognition (ICMPC8), Northwestern University School of Music, Evanston, IL, USA, 3-7 August.

Couch, S. R. (1983) 'Patronage and organizational structure in symphony orchestras in London and New York', in J. B. Kamerman and R. Martorella (eds) Performers and Performances: The Social Organization of Artistic Work, South Hadlye, MA: Bergin, pp. 109-22.

Csikszentmihalyi, M. (1997) Learning Flow: The Psychology of Engagement with Everyday Life, New York: Basic Books.

Fiedler, F. E. (1967) A Theory of Leadership Effectiveness, New York: McGraw-Hill.

Fleishman, E. A. (1973) 'Twenty years of consideration and structure', in E. A. Fleishman and J. G. Hunt (eds) Current Developments in the Study of Leadership, Carbondale and Edwardsville, IL: South Illinois University Press, pp. 1-37.

Gebert, D. (2002) Führung und Innovation, Stuttgart: Kohlhammer.

Gebert, D. and Ulrich, J. G. (1991) 'Benötigen Theorie und Praxis ein verändertes Verständnis von Führung?’, Die Betriebswirtschaft 51: 749-61.

Hersey, P. and Blanchard, K. H. (1977) Management of Organizational Behavior: Utilizing Human Resources, 3rd edn, Englewood Cliffs, NJ: Prentice-Hall.

House, R. J., Spangler, W. D. and Woycke, J. (1991) 'Personality and charisma in the U.S. presidency: a psychological theory of leader effectiveness', Administrative Science Quarterly 36: 364-96.

Krause, D. E. (2003) Macht und Vertrawen in Innovationsprozessen, Berlin: Technische Universität.

Krause, D. E. (2004) 'Influenced-based leadership as a determinant of the inclination to innovate and of innovation-related behaviours: an empirical investigation', Leadership Quarterly 15(2): $79-102$.

Krause, D. E. and Boerner, S. (2001) 'Experten führen Experten - zur Führung im Orchester', Das Orchester 49(12): 8-11.

Krause, D. E., Boerner, S., Lanwehr, R. and Nachtigall, C. (2002) 'Der Einsatz von Macht als Bedingung des Führungserfolgs im Orchester - Eine Analyse mit Hilfe linearer Strukturgleichungsmodelle', Zeitschrift für Personalpsychologie 1(3): 124-37.

Lesle, L. (1984) Der Musikkritiker - Gutachter oder Animateur?, Hamburg: Wagner. 
McDonald, R. P. (1999) Test Theory: A Unified Treatment, Mahwah, NJ: Lawrence Erlbaum. Merton, R. K. (1957) Social Theory and Social Structure, Glencoe.

Osgood, C. E., Suci, G. J. and Tannenbaum, P. H. (1957) The Measurement of Meaning, Urbana: University of Illinois Press.

Saavedra, R. P., Earley, C. and Van Dyne, L. (1993) 'Complex interdependence in taskperforming groups', Journal of Applied Behavioral Psychology 78: 61-72.

Stepanauskas, D. (2001) 'Flawed expertise: on the need to overcome the discrepancy between instrumental training and orchestral reality: the case of string players', in J. W. Davidson and H. Eiholzer (eds) The Music Practitioner: Exploring Practices and Research in the Development of the Expert Music Performance, Teacher and Listener, Aldershot: Ashgate.

Tannenbaum, R. and Schmidt, W. H. (1958) 'How to choose a leadership pattern', Harvard Business Review, March-April: $95-101$.

de Vries, R., Roe, R.A. and Taillieu, T.C.B. (1999) 'On charisma and need for leadership', European Journal of Work and Organizational Psychology 8(1): 109-33.

Vroom, V. H. and Yetton, P. W. (1973) Leadership and Decision Making, Pittsburgh, PA: University of Pittsburgh Press.

Weber, M. (1989) Wirtschaft und Gesellschaft, 6th edn, Tübingen: Mohr-Siebeck.

Yukl, G. (2002) Leadership in Organizations, 5th edn, Englewood Cliffs, NJ: Prentice Hall. 